\title{
Synthesis, Characterization and Fabrication of NTC Thick Film Thermistor Using Lead Free Glass Frit
}

\author{
Shweta Jagtap ${ }^{1}$, Sunit Rane ${ }^{2 *}$ and Suresh Gosavi ${ }^{3}$ \\ 1. Department of Instrumentation Science, Savitribai Phule Pune University, Pune 411007, India \\ 2. Renewable Energy and Sensor Materials Laboratory, Centre for Materials for Electronics Technology (C-MET), Panchawati, Off. \\ Dr. Bhabha Road, Pune 411008, India
}

3. Department of Physics, Savitribai Phule Pune University, Pune 411007, India

\begin{abstract}
Thermistors are important and attractive in microelectronic and opto- electronic systems due to their unique thermoelectric properties and their applications in air flow sensor, IR detectors, temperature sensors etc. In the present study, mixed transition manganite semiconducting ceramics with spinel structures are used for the preparation of negative temperature co-efficient (NTC) ceramic thermistor. Here, we report the preparation of NTC powders by co-precipitation of chlorides of Mn, Co, Ni and its lead free thick film thermistors. The synthesized NTC powders as well as its thick films were characterized by TGA, XRD, and SEM. The prepared thick film thermistors showed thermistor constant $(\beta)$ in the range 3,562-4,334 $\mathrm{K}$ over the temperature range of $25-250{ }^{\circ} \mathrm{C}$.
\end{abstract}

Key words: NTC thermistor, lead free, thick film, thermistor constant.

\section{Introduction}

The persisting trend towards advance thick-film hybrid circuits increases the need for simple means of temperature compensation. Also tremendous progress in equipping consumer products, automobiles and control equipments with microcomputers requires low-cost, interchangeable, and highly reliable temperature sensors. Thick film technology is being successfully used for production of various kinds of sensors due to its simplicity, possibility of making integrated and electronic conditioning circuits on one substrate at a low cost. Currently in electronic industry lead or cadmium based glass frits which are being currently used in thick film materials contain high concentration (> $50 \mathrm{vol} . \%$ ) of these elements [1-5]. However, both lead and cadmium are toxic and hazardous to human and ultimately to the environment since these compounds remains stable over the time. Therefore the recent RoHS (Restriction of Hazardous

*Corresponding author: Sunit Rane, Ph.D., senior scientist, research fields: thick film technology, nanomaterials, solar cells, high frequency microstrip components, etc.
Substances) guidelines restricted such hazardous substances from the electronic products forced the electronic industry toward environmental friendly manufacturing solutions resulting the production of selected 'green' electronic materials such as conductors and solders. On the other hand till toady, 'green' thick film resistors are not available commercially in the market but only limited academic research in particular to resistors [6-11] and thermistors [12-16] towards the formulation of 'green' resistors and thermistors have been carried out at laboratory scale.

Negative temperature co-efficient (NTC) thermistors based on semiconducting oxides are widely used in industrial and domestic applications since these are inexpensive, easy to use and therefore widely used for simple temperature measurements. These NTC materials are normally based on solid solutions of transition metal oxides namely $\mathrm{Mn}, \mathrm{Co}$, $\mathrm{Ni}$, and to achieve suitable properties of the thermistors properties, the synthesis process to obtain the NTC ceramics have to be carefully controlled. The 
functional oxides are normally prepared either by ceramic or chemical route. The materials prepared by chemical route are highly homogeneous, easy to dope the foreign ions, can produce variety of sizes, shapes and low temperature synthesizable due to high reactivity [17]. Considering the advantages of wet chemical method, more researchers have now attracted towards the use of wet chemical route for the preparation such complex materials $[5,14,16,18]$. Many researchers [13-16, 19-22] reported the preparation of NTC spinel materials by co-precipitation route and subsequently obtained the final product at 800 and $850{ }^{\circ} \mathrm{C}$ with submicron size $(100-500 \mathrm{~nm})$ for the use of thermistors. However, it was noted that in the chemical synthesis, different types of precursor materials used for the synthesis affects the final processing temperature and then ultimately the powder characteristics [21].

In this work, we report the indigenous preparation of active submicron size ntc powder material by co-precipitation of $\mathrm{MnCl}_{2}, \mathrm{CoCl}_{2}$ and $\mathrm{NiCl}_{2}$ and its lead free thick film thermistors for wide temperature range of $25-250 \quad{ }^{\circ} \mathrm{C}$ with excellent NTC characteristics.

\section{Materials and Procedure}

\subsection{Co-precipitation of Spinel Powder Using Chlorates}

NTC thermistor powder materials were prepared by co-precipitation of the metal chlorides with the oxalic acid. The proportionate molar concentration of $\mathrm{MnCl}_{2}$, $\mathrm{CoCl}_{2}$, and $\mathrm{NiCl}_{2}$ were individually dissolved in distilled water and then mixed together to form an aqueous solution by vigorously stirring for $30 \mathrm{~min}$. Similarly, stoichiometric solution of oxalic acid was prepared using distilled water and heated the same at $30{ }^{\circ} \mathrm{C}$ for complete dispersion. The prepared mixture of the chlorates was then added slowly to the oxalic acid solution with the constant stirring by magnetic needle and heated up to $40{ }^{\circ} \mathrm{C}$; the mixture precipitated at this point. The obtained precipitate was firstly washed with acetone and then again with distilled water to remove the excess chlorine. The obtained precipitate was kept under IR lamp for an hour to evaporate the water which was then subsequently dried at $110^{\circ} \mathrm{C}$ in hot air oven for $2 \mathrm{hrs}$. The dried powder lump was crushed into agate mortar to obtain the powder. The crushed powder was transferred into the alumina crucible which was sintered at $1,000{ }^{\circ} \mathrm{C}$ with a heating rate of $10{ }^{\circ} \mathrm{C} / \mathrm{min}$ for dwell time of $4 \mathrm{hrs}$ and cooled normally. The sintered mass was again crushed and pulverized to obtain the fine powder. Four set of compositions were prepared considering the phase diagram to achieve the minimum room temperature resistivity [23]. The details of the prepared sample are given in Table 1.

\subsection{Preparation of Thick Film Thermistor Pastes and Films}

Thick film thermistor pastes were formulated by mixing of the prepared NTC material, lead-free glass and an organic vehicle in an agate mortar. Throughout the experiment, the inorganic (NTC material + lead free glass frit) to organic vehicle (which is a mixture of ethyl cellulose and 2-(2-Butoxy ethyl-ethyl) acetate) ratio was maintained as $70: 30 \mathrm{wt} \%$ while that for active powder (NTC material) and glass frit (calcium-barium borosilicate) was kept at $95: 5$. The paste compositions were optimized in order to maintain the optimum viscosity, thixotropy and good printability. Planar thermistor pattern of size $10 \mathrm{~mm} \times$ $10 \mathrm{~mm}$ was screen printed on to the alumina substrate (96\%) using pre-fired lead free silver terminations for the electrical contact of the thermistor. The printed thick films were dried under IR lamp for $15 \mathrm{~min}$ for settling of the film and then fired in the thick film firing

Table 1 Details of the prepared NTC material compositions.

\begin{tabular}{ll}
\hline Sample code & Spinel powder composition \\
\hline CNTC-1 & $\mathrm{Mn}_{1.5} \mathrm{Co}_{1} \mathrm{Ni}_{0.5} \mathrm{O}_{4}$ \\
CNTC-2 & $\mathrm{Mn}_{1.5} \mathrm{Co}_{0.5} \mathrm{Ni}_{1} \mathrm{O}_{4}$ \\
CNTC-3 & $\mathrm{Mn}_{2} \mathrm{Co}_{0.8} \mathrm{Ni}_{0.2} \mathrm{O}_{4}$ \\
CNTC-4 & $\mathrm{Mn}_{2} \mathrm{Co}_{0.5} \mathrm{Ni}_{0.5} \mathrm{O}_{4}$ \\
\hline
\end{tabular}


furnace (BTU make) at $850{ }^{\circ} \mathrm{C}$ for a dwell of $10 \mathrm{~min}$ using the conventional 60 min thick film firing profile. Thickness of the fired films was measured using Tally surf profilometer and was in the range of $25 \pm 5 \mu \mathrm{m}$. The resistance versus temperature measurement was carried out using Agilent 4.5 digit multimeter (model $\mathrm{U} 1252 \mathrm{~A}$ ) in the temperature range of $25-250^{\circ} \mathrm{C}$. The prepared powders and films were characterized by thermo-gravimetric, X-ray diffraction, and SEM for microstructure analysis.

\section{Results and Discussion}

\subsection{Thermo-Gravimetric Analysis}

The thermo-gravimetric analysis of as precipitated material was carried out in the temperature range of $30-900{ }^{\circ} \mathrm{C}$ at the heating rate of $10{ }^{\circ} \mathrm{C} / \mathrm{min}$ in the nitrogen medium. Fig. 1 shows the thermogram of the representative sample (CNTC-3). The thermogram indicates the thermal decomposition of the material with two stages of weight loss; first around $200{ }^{\circ} \mathrm{C}$ corresponding to the removal of water contents present in the material. The second weight loss around $400{ }^{\circ} \mathrm{C}$ is due to dehydration of oxalate and decomposition of anhydrous oxalate. Beyond $400{ }^{\circ} \mathrm{C}$, the thermogram remains constant indicating thermal stability of the composition. Based on the above TG results, the precipitated powders were sintered at $1,000{ }^{\circ} \mathrm{C}$ to obtain the thermodynamically stable material.

\subsection{X-Ray Diffraction Analysis}

X-ray diffraction analysis of the sintered ntc powder was carried out using $\mathrm{CuK} \alpha$ radiation in the angle $(2 \theta)$ range of $20^{\circ}-80^{\circ}$. Fig. 2 exhibits the X-ray diffractogram for the representative powder sample (CNTC-3) sintered at $1,000{ }^{\circ} \mathrm{C}$ for $4 \mathrm{hrs}$ which highlighted existence of spinel phases of the solid solutions like $\mathrm{NiMn}_{2} \mathrm{O}_{4}, \mathrm{NiCo}_{2} \mathrm{O}_{4}$ and $\mathrm{CoMn}_{2} \mathrm{O}_{4}$. Small deviation of the peaks from the standard one is attributed to the material preparation technique used. The peaks at $\mathrm{d}$ values $2.48,2.44$ and 2.08 correspond to the maximum intensity of $\mathrm{NiCo}_{2} \mathrm{O}_{4}, \mathrm{CoMn}_{2} \mathrm{O}_{4}$, $\mathrm{NiMn}_{2} \mathrm{O}_{4}$ phases respectively.

\subsection{Microstructure Analysis}

The surface morphology of the prepared powders

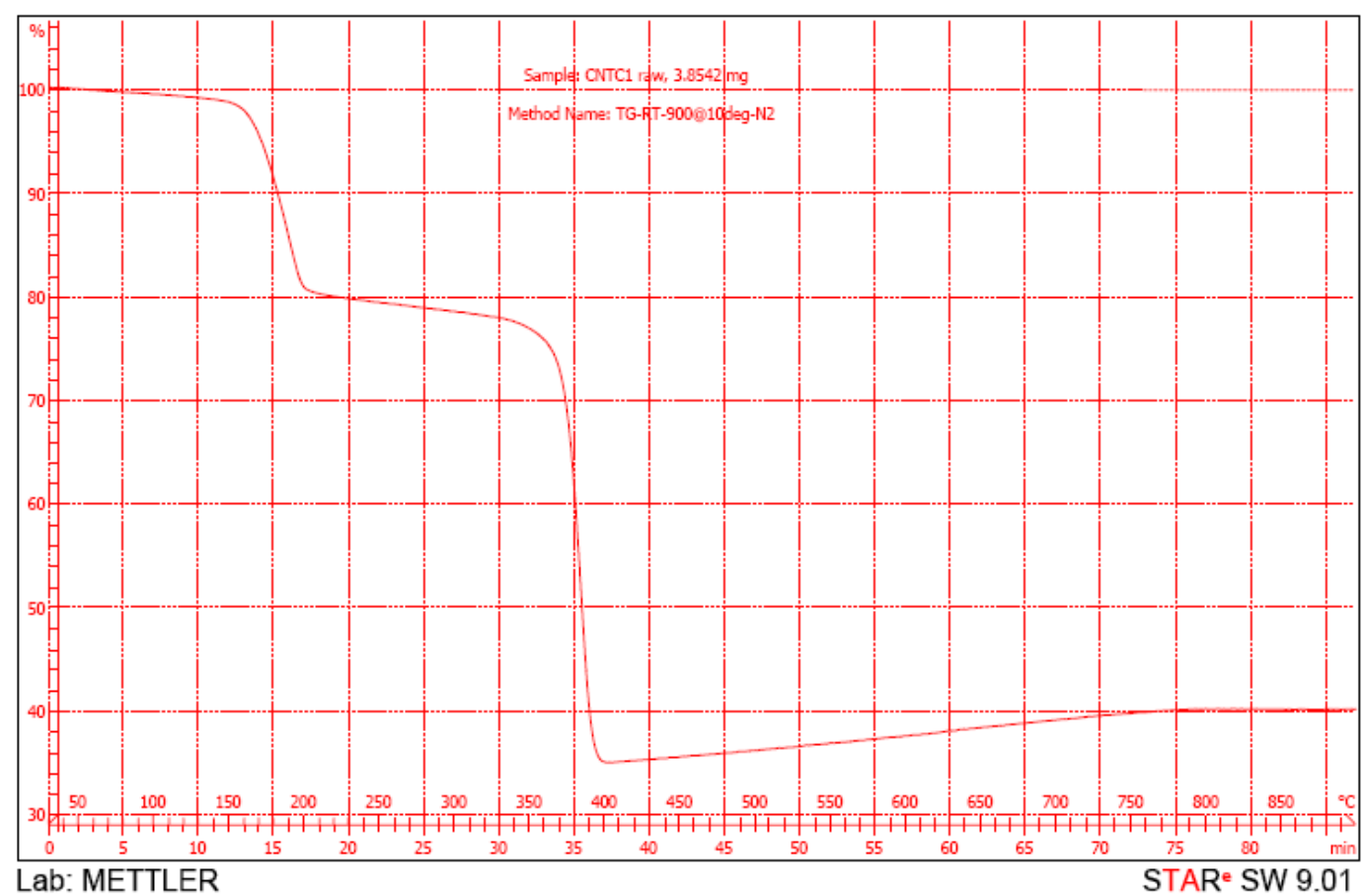

Fig. 1 Thermogram of the prepared powder sample (CNTC-3). 


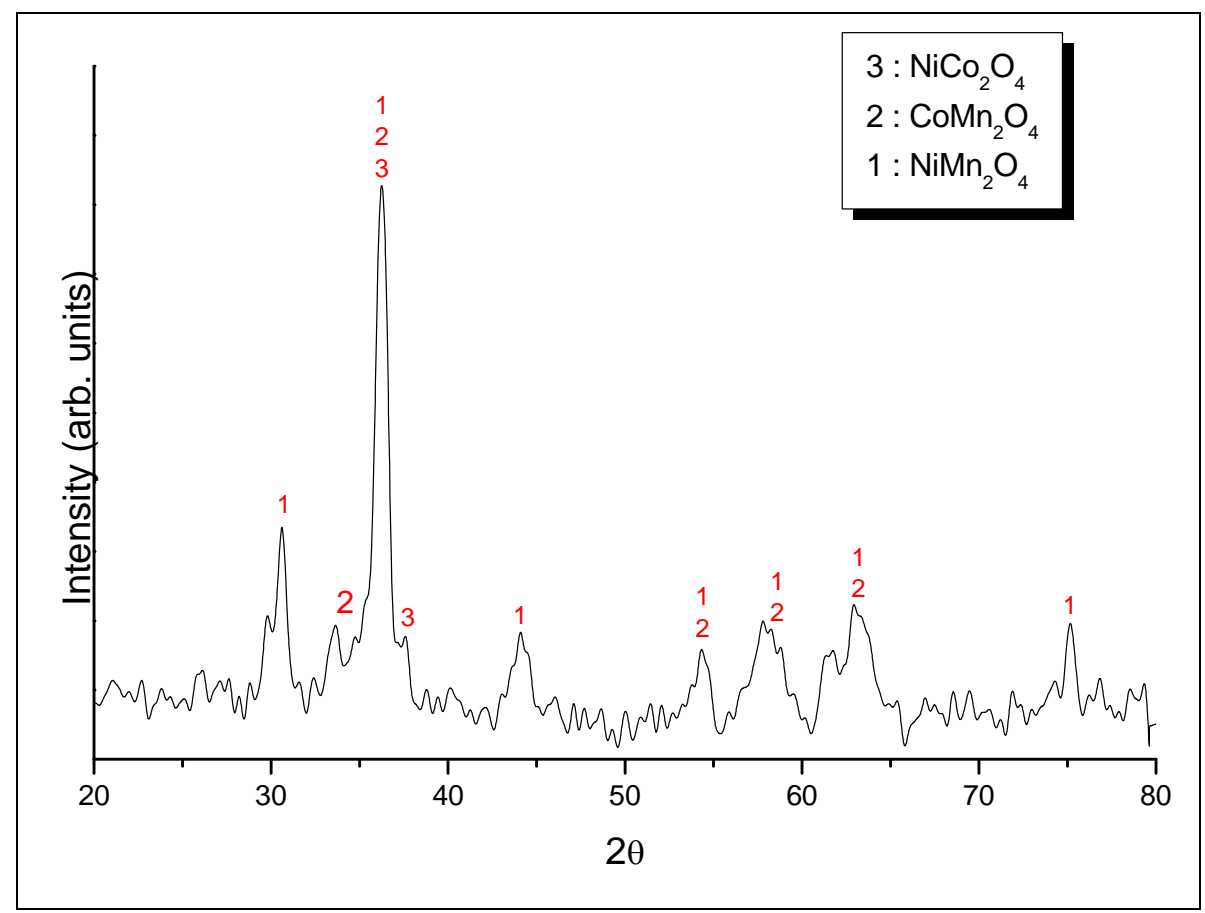

Fig. 2 X-ray diffractogram of the powder sample (CNTC-3) sintered at 1,000 ${ }^{\circ} \mathrm{C}$ for $4 \mathrm{hrs}$.

and the fired films were observed under scanning electron microscope (SEM).

All the samples studied showed almost similar surface morphology and microstructure. Therefore, to avoid the repetitiveness, the SEM micrograph of the CNTC-1 sample is shown in Fig. 3. The particle size of powder is approximately in the range of $500 \mathrm{~nm}-1 \mu \mathrm{m}$.

Fig. 4 depicts the backscattered SEM images obtained from the surface of fired thick film sample CNTC-3. The microstructure of the thick film revealed the denser and smoother surface with connected grain boundaries. It is also observed that the oxide particles are homogeneously dispersed in glassy matrix and the grain growth in the film confirms the sintering of the film. However, as expected, some small pores are also seen on the surfaces of the film which are occurred due to the evolution of trapped gases while burning of organic binders existed in thick film paste during firing process [9-10, 12-15].

\subsection{Measurement of Thermistor Properties}

The primary characteristic of the thermistor is the capability of change in their electrical resistance with change in body temperature. The temperature dependence of resistivity $(\rho)$ of the thermistor for electron hopping process is represented by "Arrhenius Eq. (1)":

$$
\rho=\rho_{0} \exp (\beta / \mathrm{T})
$$

where, $\rho_{0}$ is the resistivity of the material at infinite temperature, $\beta$ is thermistor constant and $\mathrm{T}$ is the absolute temperature [2, 18, 24-27].

The change in resistance of the thick film thermistors were measured as a function of temperature. As expected in the negative temperature coefficient thermistors, the resistance of our samples shows exponential decay with the increase in the temperature as plotted in Fig. 5. The log of resistance against reciprocal of temperature of the samples is plotted and shown in Fig. 6. All the NTC thermistor compositions operate steadily with the straight line relationship between the parameters over a wide temperature range. The data on the electrical parameters such as sheet resistance, thermistor constant and activation energy, which is the most important characteristics of the technical interest for NTC thermistor, are summarized in the Table 2. 


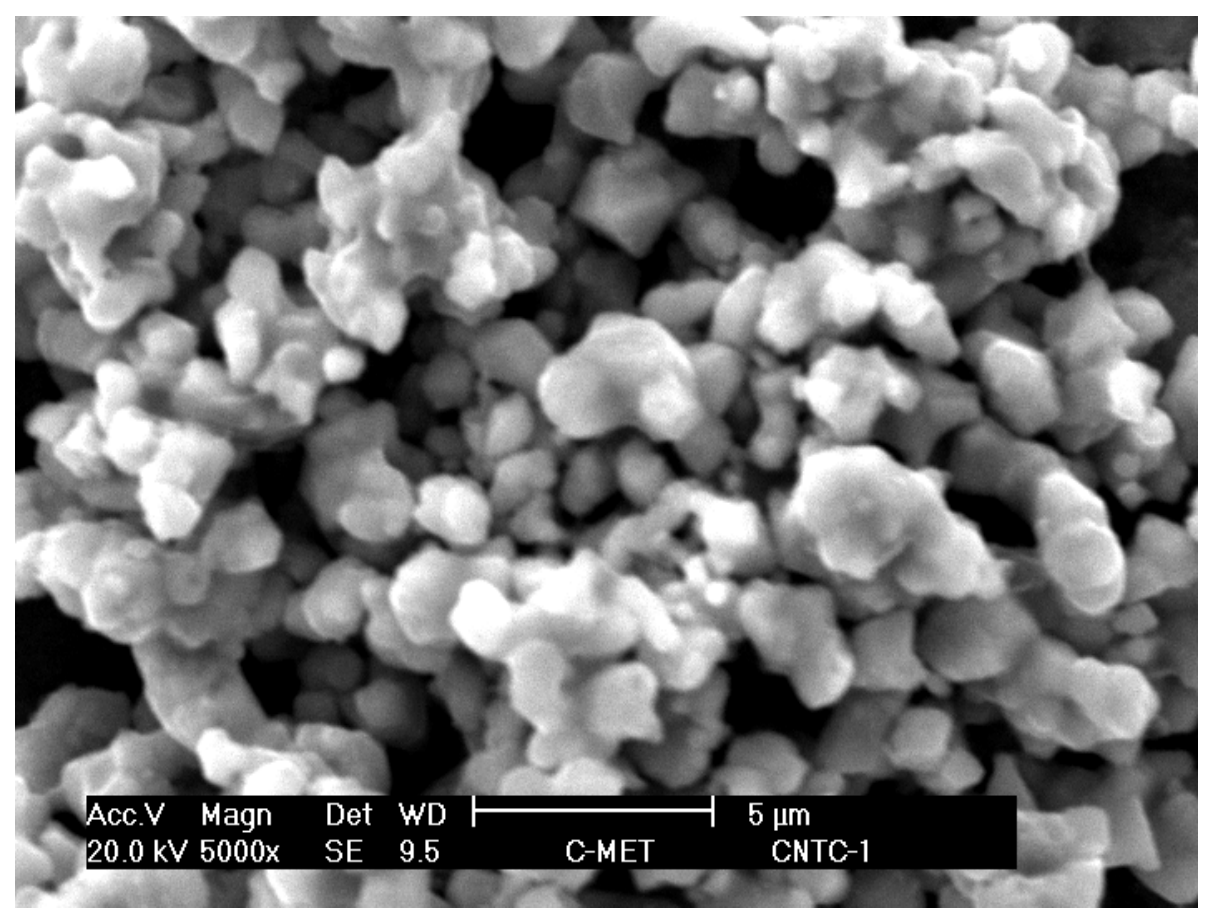

Fig. 3 SEM image of the sintered powder sample (CNTC-1).

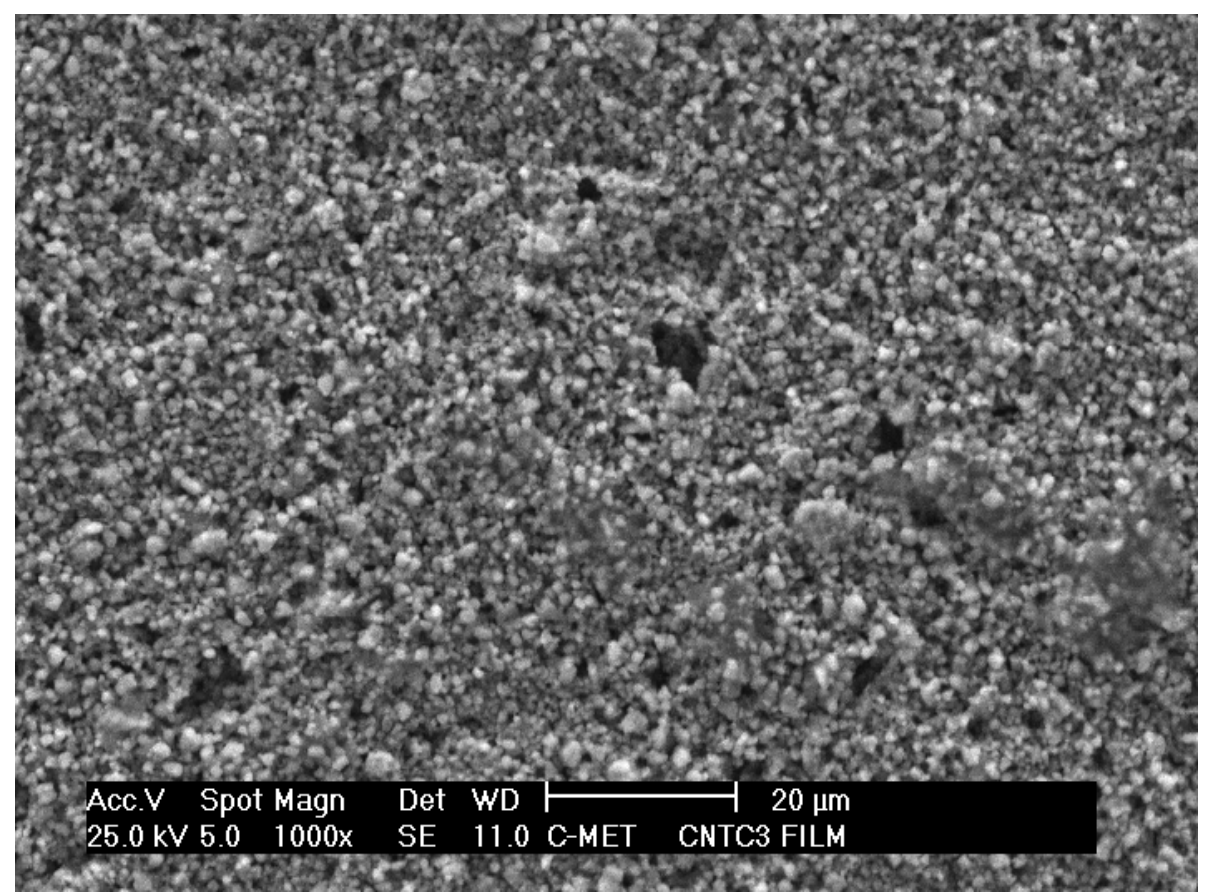

Fig. 4 Backscattered SEM images obtained from the surface of fired thick film sample (CNTC-3).

It is seen from Table 2 that the values of sheet resistance and thermistor constant depending upon the NTC material composition. The sheet resistance and the thermistor constant of the prepared samples are measured in the range of 9.78-484.3 $\mathrm{M} \Omega$ and
3500-4400 K respectively. The sample CNTC-3 shows lowest resistance value $(9.78 \mathrm{M} \Omega)$ with very excellent sensitivity index/thermistor constant $(\beta)$ $3,957 \mathrm{~K}$. Here it may be noted that even though the sample compositions were selected according to the 

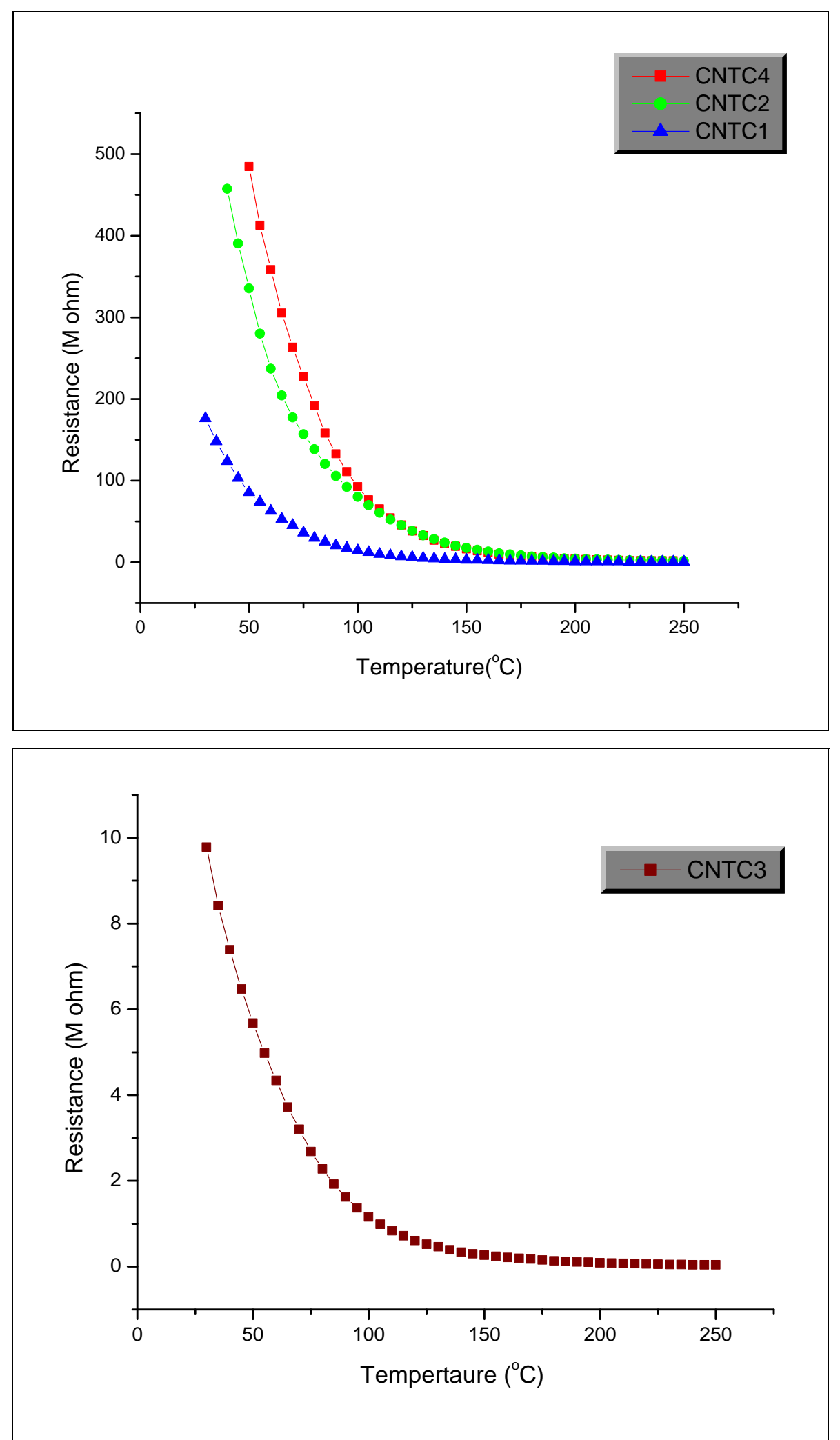

Fig. 5 Plot of resistance versus Temperature corresponds to samples (a) CNTC-1, CNTC-2 and CNTC-4 (b) CNTC-3. 


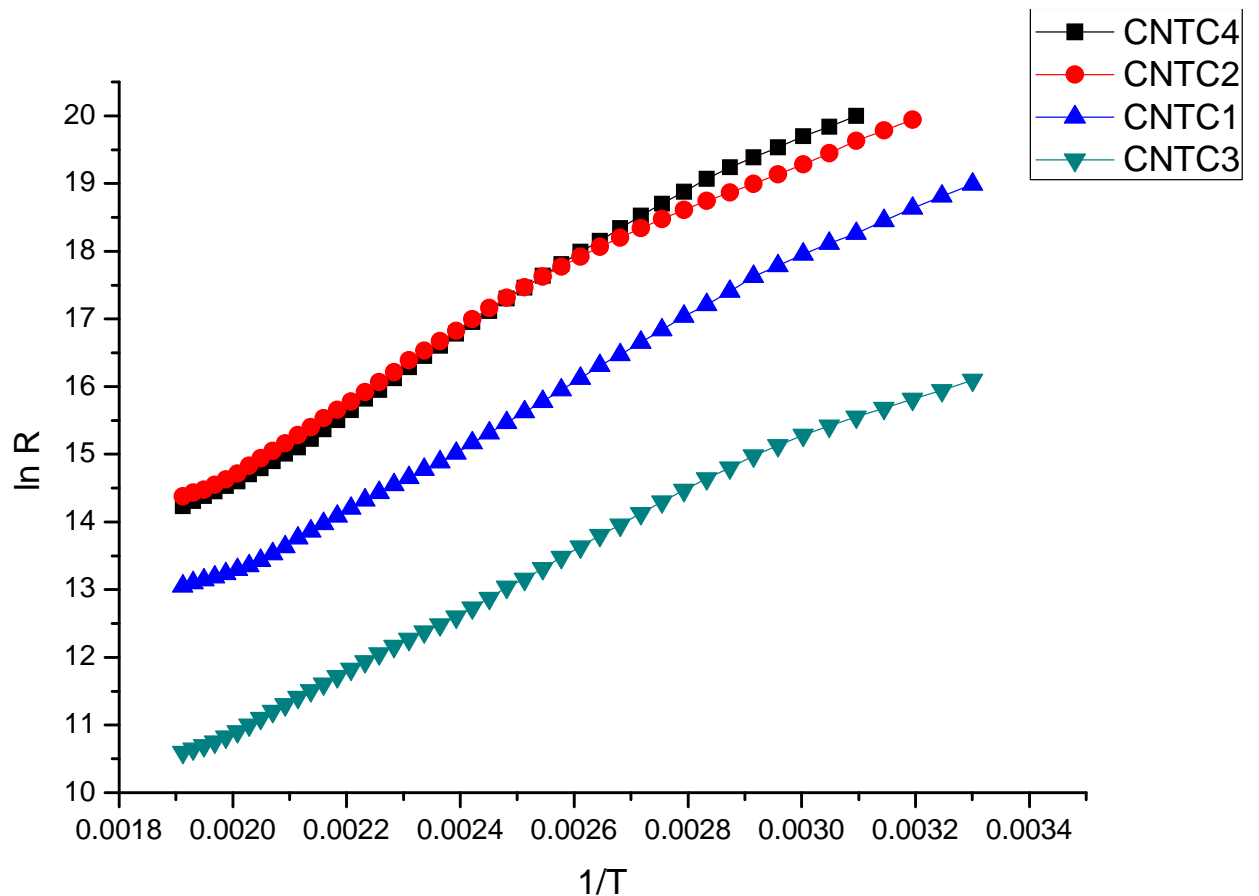

Fig. 6 Plot of Log of Resistance versus Reciprocal of Temperature of samples (a) CNTC-1, CNTC-2 and CNTC-4 (b) CNTC-3.

Table 2 Data on electrical parameters viz. sheet resistance, thermistor constant and activation energy.

\begin{tabular}{llll}
\hline Sample code & Sheet resistance $(\mathrm{M} \Omega / \square \pm 5 \%)$ & Thermistor constant $(\beta)$ & Activation energy $(\mathrm{eV})$ \\
\hline CNTC-1 & 176.2 & 4,275 & 0.3687 \\
CNTC-2 & 457.3 & 4,334 & 0.3738 \\
CNTC-3 & 9.78 & 3,957 & 0.3412 \\
CNTC-4 & 484.3 & 3,562 & 0.3072 \\
\hline
\end{tabular}

phase diagram to achieve the low room temperature resistance, the prepared samples depicts high resistance values. This might be due to the glass frit that was added in the thick film for the binding purpose, contributing to the increase in resistance. However, based on the above results, we can say that the prepared lead free thick film thermistors are very good thermal sensors with good thermistor constant or sensitivity index and these values are compatible to the presently available lead based thick film thermistors.

\section{Conclusions}

We reported the preparation of NTC ceramics by co-precipitation of chlorides of $\mathrm{Mn}, \mathrm{Co}$, and $\mathrm{Ni}$ chlorides and by sintering the precipitate at $1,000{ }^{\circ} \mathrm{C}$ for $4 \mathrm{hrs}$. Existence of cubic spinel phases like
$\mathrm{NiMn}_{2} \mathrm{O}_{4}, \mathrm{CoMn}_{2} \mathrm{O}_{4}$ and $\mathrm{NiCo}_{2} \mathrm{O}_{4}$ was confirmed by the $\mathrm{X}$-ray diffraction analysis. The particle size of the sintered spinel powder was in the range of $500 \mathrm{~nm} \sim$ $1 \mu \mathrm{m}$. The lead free thick film thermistors prepared using these powders and glass frit showed very good microstructure, homogeneity, reproducibility of the electrical parameters and high sensitivity over the wide temperature range $\left(25-250{ }^{\circ} \mathrm{C}\right)$ useful in fabricating accurate temperature sensors. The room temperature resistance and thermistor constant of the thick film thermistor are in the range of 9.78-484.3 $\mathrm{M} \Omega$ and, 3,562-4,334 K respectively. The sample CNTC-3 shows lowest resistance $(9.78 \mathrm{M} \Omega)$ with sensitivity index ( $\beta$ ) of $3,957 \mathrm{~K}$. Therefore, we can say that the required resistivity and thermistor constant can be achieved by adjusting the powder spinel composition. 


\section{Acknowledgements}

The authors express to their appreciation to $\mathrm{Mr}$. Ramakant for his assistance in the experimentation.

\section{References}

[1] Prudenziati, M. (Ed.) 1994. Handbook of Thick Film Sensors and Actuators: Thick Film Sensors, Vol. 1, Elsevier Science B. V., Amsterdam, the Netherlands.

[2] Arima, H. 1994. "Thick Film Thermistors and RTDs." in Prudenziati, M. (Ed.), Handbook of Thick Film Sensors and Actuators: Thick Film Sensors, Vol. 1, Elsevier Science B.V., Amsterdam, the Netherlands, 127.

[3] Schmidt, R., Stiegelschmitt, A., Roosen, A. and Brinkman, A. 2003. "Screen Printing of Co-precipitated $\mathrm{NiMn}_{2} \mathrm{O}_{4+\delta}$ for Production of NTCR Thermistors." $J$. European Ceramic Soc. 23: 1549-58.

[4] Hrovat, M., Belavic, D., Holc, J. and Cilensek, J. 2006. "The Development of Microstructural and Electrical Characteristics of NTC Thick Film Thermistors during Firing.” J. Material Sci. 41: 5900.

[5] Jagtap, S., Rane, S., Mulik, U. and Amalnerkar, D. 2007. "Thick Film NTC Thermistor for Wide Range of Temperature Sensing." Micorelectronics International 24: 7.

[6] Prudenziati, M., Zanardi, F., Morten, B. and Gualtiri, A. 2002. "Lead Free Thick Film Resistors: an Explorative Investigation." J. Materials Science: Materials in Electronics 13: 31-7.

[7] Rane, S., Prudenziati, M., Morten, B., Golonka, L. and Dziedzic, A. 2005. "Structural and Electrical Properties of Perovskite Ruthenate Based Lead Free Thick Film Resistors on Alumina and LTCC." J. Mat. Sci.: Mater. in Electronics 16: 687-91.

[8] Busana, M., Prudenziati, M. and Hormadaly, J. 2006. "Microstructure Development and Electrical Properties of $\mathrm{RuO}_{2}$-Based Lead-Free Thick Film Resistors." $J$. Materials Science: Materials in Electronics 17: 951.

[9] Rane, S., Prudenziati, M. and Morten, B. 2007. "Environment Friendly Perovskite Ruthenate Based Thick Film Resistors." Materials Lett 61: 595-9.

[10] Kshirsagar, A., Rane, S., Mulik, U. and Amalnerkar, D. 2007. "Microstructure and Electrical Performance of Ecofirendly Thick Film Resistor Compositions Fired at Different Firing Conditions." Materials Chemistry and Phys. 101: 492-8.

[11] Jagtap, S., Rane, S., Gosavi, S. and Amalnerkar, D. 2009. "Environmentally Sustainable Composite Resistors with Low Temperature Coefficient of Resistance." Microelectronics International 25: 19.

[12] Jagtap, S., Rane, S., Gosavi, S. and Amalnerkar, D. 2008.
"Preparation, Characterization and Electrical Properties of Spinel Type Environment Friendly Thick Film NTC Thermistors.” J. European Ceramic Soc. 28: 2501.

[13] Jagtap, S., Rane, S., Aiyer, R., Gosavi, S. and Amalnerkar, D. 2010. "Study of Microstructure, Impedance and DC Electrical Properties of $\mathrm{RuO}_{2}$ Spinel Based Screen Printed Green NTC Thermistor." Current Applied Physics 10: 1156.

[14] Jagtap, S., Rane, S., Gosavi, S. and Amalnerkar, D. 2010. "Low Temperature Synthesis and Characterization of NTC Powder and its Lead Free Thick Film Thermistors." Microelectronic Engineering 87: 104.

[15] Jagtap, S., Rane, S., Gosavi, S. and Amalnerkar, D. 2010. "Lead Free Thick Film Thermistors: A Study of Variation in Glass Frit Concentration and Organics Composition." J. Materials Science: Materials in Electronics 21: 861.

[16] Jagtap, S., Rane, S., Gosavi, S. and Amalnerkar, D. 2011. "Study on I-V Characteristics of Lead Free NTC Thermistor for Self Heating Application." Microelectronics Engineering 88: 82.

[17] Kulkarni, S. K. 2007. "Nanotechnlogy: Principles and Practices." Capital Publishing Co. New Delhi, India.

[18] Macklen, E. 1979. "Thermistors." Electrochemical Publication Ltd. Ayr, Scotland.

[19] Ashcroft, G., Terry, I. and Gover, R. 2006. "Study of the Preparation Conditions for $\mathrm{NiMn}_{2} \mathrm{O}_{4}$ Grown from Hydroxide Precursors. J. European Ceramic Soc. 26: 901.

[20] Gao, J. Fang, D., Wang, Z., Yang, P. and Chen, C. 2007. "Preparation and Electrical Properties of Copper-Nickel Manganite Ceramic Derived from Mixed Oxalate." Sensors and Actuators A: Physical 135: 472.

[21] Jagtap, S. 2009. "Synthesis and Characterization of Nanosize Mn-Co-Ni-Ru Oxide NTC Thermistor Material and Fabrication of its Eco-friendly Thick Film Temperature Sensor." Ph. D. Thesis, Pune University, Pune, India.

[22] Jagtap S., Rane S., Gosavi S., Mulik U. and Amalnerkar D. 2013. 'Infrared Properties of 'Lead Free' Thick Film NTC Thermo-Resistive Sensor Based on the Mixture of Spinel Material and $\mathrm{RuO}_{2}$." Sensors \& Actuators A: Physical 197C: 166-70.

[23] Vittal, N. 1990. "Formulation and Characterization of Thick Film Thermistor Compositions Applied as Sensor in Hybrid Microelectronics." Ph.D. Thesis, Pune University, Pune, India.

[24] Martin De Vidales J. L., Garcia-Chain, P., Rojas, R. M., Vila, E. and Garcia-Martinez, O. 1998. "Preparation and Characterization of Spinel-Type Mn-Ni-Co-O Negative Temperature Coefficient Ceramic Thermistors." J. Materials Science 33: 1491-6.

[25] Legros, R., Metz R. and Rousset, A. 1990. "Structural 
Properties of Nickel Manganite $\mathrm{Ni}_{\mathrm{x}} \mathrm{Mn}_{3-\mathrm{x}} \mathrm{O}_{4}$ with $0.5 \leq \mathrm{x}$ $\leq 1$." J. Materials Science 25: 4410-4.

[26] Abe, Y., Meguro, T., Yokoyama, T., Morita, T., Tatami, J. and Komeya, K. 2003. "Electrical Properties of Sintered Bodies Composed of a Monophase Cubic Spinel
Structure $\mathrm{Mn}_{(1.5-0.5 \mathrm{X})} \mathrm{Co}_{(1+0.5 \mathrm{X})} \mathrm{Ni}_{0.5} \mathrm{O}_{4}(0 \leq \mathrm{X} \leq 1)$." J. of Ceramic Processing Research 4: 140.

[27] Kanade, S. and Puri, V. 2006. "Composition Dependent Resistivity of Thick Film $\mathrm{Ni}_{(1-\mathrm{x})} \mathrm{Co}_{\mathrm{x}} \mathrm{Mn}_{2} \mathrm{O}_{4}$ : $(0 \leq \mathrm{x} \leq 1)$ NTC Thermistors." Materials Lett. 60: 1428-31. 